\title{
Predictors of coronary collaterals in patients with non ST-elevated acute coronary syndrome: the paradox of the leukocytes
}

\author{
ERHAN TENEKECIOGLU ${ }^{1}$, MUSTAFA YILMAZ ${ }^{1}$, KEMAL KARAAGAC ${ }^{\prime}$, ADEM BEKLER ${ }^{2}$, \\ BURHAN ASLAN ${ }^{l}$, SERAFETTIN DEMIR ${ }^{3}$, MUSTAFA KUZEYTEMIZ ${ }^{l}$ \\ ${ }^{1}$ Bursa Yuksek Ihtisas Education and Research Hospital, Cardiology Clinic, Bursa, Turkey \\ ${ }^{2}$ Çanakkale Onsekiz Mart University, Medicine School, Cardiology, Turkey \\ ${ }^{3}$ Adana State Hospital, Cardiology Clinic, Turkey
}

\begin{abstract}
Aim of the study: Atherosclerosis represents active inflammation in which leukocytes play significant role. Coronary collateral development is a response to myocardial ischaemia. In this study we aimed to investigate the association of the leukocytes with coronary collateral development in patients with non ST-elevated acute coronary syndromes (NST-ACS).

Material and methods: A total of 251 consecutive patients were hospitalized in our hospital with a diagnosis of NST-ACS. The blood samples were collected 1-hour after admission to the hospital and peripheral leukocytes (neutrophils, monocytes and lymphocytes) were examined. All patients underwent coronary angiography. The coronary collateral vessels $(C C V)$ are graded according to the Rentrop scoring system.

Results: Group 1 consisted of 146 patients with Rentrop 0 and Group 2 consisted of 105 patients with Rentrop 1, 2 and 3. The presence of CCV was significantly associated with neutrophil count, lymphocyte count, monocyte count and neutrophil-lymphocyte ratio (NLR). In subgroup analyses, higher NLR was significantly associated with good CCV development in patients with NST-ACS.

Conclusions: Higher neutrophil count, monocyte count and NLR and lower lymphocyte count on admission, were associated with the presence of CCV in patients with NST-ACS. High NLR may predict good collateral development in patients with NST-ACS.
\end{abstract}

Key words: leukocytes, angiogenesis, coronary collateral vessel.

(Centr Eur J Immunol 2014; 39 (1): 83-90)

\section{Introduction}

Atherosclerosis represents an active inflammation in which leukocytes play a significant role [1]. Neutrophil count, lymphocyte count and neutrophil-to-lymphocyte ratio (NLR) are readily available biomarkers that give important information about the inflammatory activity during the acute phase of the coronary syndrome [2]. Neutrophil to lymphocyte ratio was also reported as an independent predictor for mortality and myocardial infarction in coronary artery diseases [3].

Coronary collateral development is a response to myocardial ischaemia [4]. This adaptive circulation protects the myocardium from ischaemic episodes, improves the myocardial contractility and reduces anginal symptoms and cardiovascular events [5, 6]. Well-developed coronary collateral prolongs the substantial time from the onset of a myocardial infarct to successful coronary reperfusion [7].
The role of the inflammation in myocardial ischaemia which is the primary stimulant for coronary collateral development, has been reported previously [8]. Despite similar degrees of coronary stenosis, the discrepancy in collateral formation may be related to different effects of inflammatory cells [8].

In this study we aim to investigate the association of white blood cell subtypes and NLR with coronary collateral development in patients with non ST-elevated acute coronary syndromes (NST-ACS).

\section{Material and methods}

A total of 251 consecutive patients were hospitalised in our hospital with a diagnosis of NST-ACS. Acute coronary syndrome (ACS) was defined as presentation with symptoms of ischaemia in association with electrocardiograph-

Correespondence: Erhan Tenekecioglu, MD, Bursa Yuksek Ihtisas Education and Research Hospital, Cardiology Clinic, 16100 Bursa, Turkey, e-mail: erhantenekecioglu@yahoo.com 
ic changes, positive cardiac enzymes, new documentation of coronary artery disease or the previous coronary artery disease diagnosis as defined by similar previous studies [9]. Symptomatic patients were assessed by a standard diagnostic flowchart that included clinical and electrocardiographic monitoring as well as biochemical measurements of myocardial necrosis markers. Patients diagnosed with acute myocardial infarction (AMI) with non-ST elevation (nonSTEMI) $(n=154)$, and unstable angina (UA) $(n=92)$ were included in this study. The study protocol was approved by the institutional review board in our centre, and informed consent was obtained from all patients. Demographic characteristics, medical histories, laboratory studies including leukocyte counts and peripheral differential counts, and a variety of hospital outcome data were collected. Clinical information included data on systemic hypertension (HT), diabetes mellitus (DM), hyperlipidaemia, smoking, previous history of coronary artery disease (CAD), including coronary angioplasty or myocardial revascularisation, and early family history of CAD. Diabetes mellitus was determined by physician report and was based on a fasting blood sugar level $\geq 126 \mathrm{mg} / \mathrm{dl}$ or the use of an anti-diabetic medication. Hypertension was physician-reported for systolic blood pressure $\geq 140 \mathrm{~mm} \mathrm{Hg}$, diastolic blood pressure $\geq 90 \mathrm{~mm}$ $\mathrm{Hg}$, or use of anti-hypertensive agents. Hyperlipidaemia was physician reported for total cholesterol $\geq 200 \mathrm{mg} / \mathrm{dl}$, low-density lipoprotein level $\geq 130 \mathrm{mg} / \mathrm{dl}$, or use of cholesterol-lowering medication. Family history was self-reported when a first order relative had suffered cardiovascular death, myocardial infarction (MI), or coronary revascularisation before age 65 . Smoking included active or previous ( $>10$ pack-years) tobacco use. The blood sample for neutrophil count, lymphocyte count and NLR assessment was collected 1 hour after admission to the hospital. In our hospital, blood samples are collected from the ante-cubital vein by an atraumatic puncture and are sent to the laboratory for analysis within 1 hour after collection. Venous blood is collected in a tube containing K3 EDTA for measurement of haematological indices in all patients undergoing the coronary angiography. Haematological indices are evaluated from CBC (complete blood count) analysis performed by a Coulter LH 780 Hematology Analyser (Beckman Coulter Ireland Inc. Mervue, Galway, Ireland). Coronary angiographies were performed in our clinic using the standard Judkins technique [10]. The coronary artery angiography films were reviewed by two experienced cardiologists blinded to the clinical and demographic data for all patients. The recorded data also included the number of diseased vessels, the vessel to which the collaterals were connected, and the grade of coronary collateral circulation. Vessels exhibiting a $70 \%$ or greater reduction in lumen diameter were classified as significant CAD. In subjects with more than one significant $C A D$ vessel, the vessel with the highest collateral grade was chosen for analysis. Collateral flow was graded according to the Rentrop classification: $0=$ no filling of any collateral circulation, $1=$ filling of side branches of the artery to be perfused by collateral circulation, $2=$ partial filling of the epicardial artery by collateral circulation, and 3 = complete filling of the epicardial artery by collateral circulation [11]. Patients were then classified according to presence of collateral circulation as either collaterals absent (grade 0 collateral circulation) (Group 1) or collaterals present (grade 1, grade 2 or grade 3 collateral circulation) (Group 2). In subgroup analyses, the patients were divided into two groups according to the status of the coronary collateral development; patients with poor coronary collaterals (patients with Rentrop 0 and Rentrop 1) and patients with good collaterals (patients with Rentrop 2 and Rentrop 3). Patients with a history of trauma, surgery, neoplasm, or infectious disease in the last 30 days prior to hospitalisation as well as current use of immunosuppressants (including systemic, inhaled and topical corticosteroids) and chronic systemic inflammatory diseases such as rheumatoid arthritis, chronic obstructive pulmonary disease, asthma etc. were excluded from the study. We also excluded any patients with history of post-admission complications such as cardiogenic shock, serious arrhythmias with haemodynamic instability, or heart failure.

\section{Statistical analysis}

The primary outcome of interest was the presence of coronary collateral vessels (CCVs), defined as a Rentrop grade $\geq 1$. Normal distribution was assessed by the Kolmogorov-Smirnov test. Variables which did not follow a normal distribution were expressed as median and inter-quartile range, whereas other continuous variables were expressed as means \pm standard deviation; categorical variables were expressed as proportions. Continuous variables were compared by Student's $t$-test or Mann-Whitney $U$ test as appropriate. Chi-square test was used to compare categorical data. The Pearson's (for parametric variables) and Spearman's (for nonparametric variables) rank correlation coefficient was used for correlation analysis between Rentrop score (ordinal variable, grade 0-3) and other variables. The relation between the degree of CCVs and the cardiac troponin I (cTnI), total number of diseased vessels, white blood cell count, neutrophil count and monocyte count was quantified with linear logistic regression analysis with adjustment for gender, age, a history of MI. Odds ratios (ORs) and 95\% confidence interval are presented. All $p$ values were two-sided with a significance level of $p<0.05$. The Statistical Package for the Social Sciences 20.0 for Windows (SPSS Inc., Chicago, IL) was used for statistical analysis.

\section{Results}

\section{Clinical characteristics}

The baseline characteristics of the subjects are presented in Tables 1 and 2. There was no gender differ- 
Table 1. Baseline clinical characteristics of patients

\begin{tabular}{|c|c|c|c|}
\hline Variable & $\begin{array}{c}\text { Group 1 } \\
\text { (Rentrop 0) }\end{array}$ & $\begin{array}{c}\text { Group 2 } \\
\text { (Rentrop } \\
1,2,3)\end{array}$ & $p$ \\
\hline Gender (M/F), $n$ & $108 / 38$ & $83 / 22$ & 0.35 \\
\hline Age (years) & $60.2 \pm 11.8$ & $62.5 \pm 12.5$ & 0.13 \\
\hline BMI $\left(\mathrm{kg} / \mathrm{m}^{2}\right)$ & $27.6 \pm 3.8$ & $27.2 \pm 3.7$ & 0.42 \\
\hline $\operatorname{HT}(n, \%)$ & $79(54 \%)$ & $49(46 \%)$ & 0.24 \\
\hline $\mathrm{DM}(\%)$ & $35(24 \%)$ & $33(31 \%)$ & 0.19 \\
\hline Total cholesterol (mg/dl) & $197 \pm 48$ & $195 \pm 53$ & 0.78 \\
\hline LDL cholesterol (mg/dl) & $124 \pm 44$ & $124 \pm 42$ & 0.98 \\
\hline HDL-C (mg/dl) & $43 \pm 16$ & $42 \pm 12$ & 0.49 \\
\hline $\mathrm{TG}(\mathrm{mg} / \mathrm{dl})$ & $146 \pm 65$ & $164 \pm 88$ & 0.18 \\
\hline Smoking $(n, \%)$ & $53(36 \%)$ & $47(44 \%)$ & 0.78 \\
\hline Previous PCI, $n(\%)$ & $15(10 \%)$ & $13(12 \%)$ & 0.98 \\
\hline Previous CABG, $n(\%)$ & $1(0.6 \%)$ & $1(0.9 \%)$ & 0.81 \\
\hline $\begin{array}{l}\text { Total diseased coronary } \\
\text { arteries }(n)\end{array}$ & $1.82 \pm 0.76$ & $2.20 \pm 0.82$ & $\begin{array}{c}< \\
0.001\end{array}$ \\
\hline \multicolumn{4}{|l|}{$\begin{array}{l}\text { Severely diseased } \\
\text { coronary }\end{array}$} \\
\hline LAD & 66 & 35 & \multirow{3}{*}{0.143} \\
\hline $\mathrm{Cx}$ & 47 & 38 & \\
\hline $\mathrm{RCA}$ & 33 & 32 & \\
\hline $\begin{array}{l}\text { Presence of ischaemic } \\
\text { ECG changes }(\%)\end{array}$ & $72 \%$ & $73 \%$ & 0.62 \\
\hline $\mathrm{CK}(\mathrm{U} / \mathrm{l})$ & $374 \pm 151$ & $382 \pm 132$ & 0.97 \\
\hline CK-MB (U/l) & $39 \pm 25$ & $40 \pm 28$ & 0.72 \\
\hline Troponin I (ng/ml) & $5.2 \pm 1.1$ & $9.9 \pm 4.5$ & 0.04 \\
\hline
\end{tabular}

ence between groups 1 and $2(p=0.35)$. The patients with CCVs were non-significantly older than the patients without CCVs $(p=0.13)$. Significant differences between the groups were not observed for body mass index (BMI), HT, DM, heart rate, total cholesterol, low-density lipoprotein cholesterol (LDL-C), high-density lipoprotein cholesterol (HDL-C), triglyceride (TG), smoking, creatine kinase $(\mathrm{CK})$, creatine kinase isoenzyme MB (CK-MB), previous MI history, previous coronary artery by-pass greft (CABG) history, previous percutaneous coronary intervention (PCI) history, presence of ischaemic electrocardiography (ECG) changes, time interval between chest pain and admision to hospital and platelet count. Compared to patients without collaterals, cTnI was higher in patients with collaterals $(5.2 \pm 1.1$ vs. $9.9 \pm 4.5 ; p=0.04)$. The patients with collaterals had
Table 2. Baseline blood parameters of patients

\begin{tabular}{lccc}
\hline Variable & $\begin{array}{c}\text { Group 1 } \\
\text { (Rentrop 0) }\end{array}$ & $\begin{array}{c}\text { Group 2 } \\
\text { (Rentrop } \\
\mathbf{1 , 2 , 3}\end{array}$ & $\boldsymbol{p}$ \\
\hline Hemoglobin $(\mathrm{g} / \mathrm{dl})$ & $13.3 \pm 2.8$ & $12.9 \pm 1.6$ & 0.21 \\
\hline $\begin{array}{l}\text { White blood cell count } \\
\left(10^{3} / \mu \mathrm{l}\right)\end{array}$ & $9.31 \pm 2.62$ & $10.24 \pm 2.68$ & 0.006 \\
\hline $\begin{array}{l}\text { Neutrophil count } \\
\left(10^{3} / \mu \mathrm{l}\right)\end{array}$ & $5.74 \pm 2.12$ & $7.54 \pm 2.87$ & 0.002 \\
\hline $\begin{array}{l}\text { Lymphocytes count } \\
\left(10^{3} / \mu \mathrm{l}\right)\end{array}$ & $2.41 \pm 1.02$ & $1.81 \pm 0.85$ & 0.08 \\
\hline $\begin{array}{l}\text { Monocyte count } \\
\left(10^{3} / \mu \mathrm{l}\right)\end{array}$ & $0.66 \pm 0.21$ & $0.78 \pm 0.32$ & 0.005 \\
\hline $\begin{array}{l}\text { Neutrophil/lymphocyte } \\
\text { ratio }\end{array}$ & $3.18 \pm 1.25$ & $4.68 \pm 2.13$ & 0.001 \\
\hline Platelet count $\left(\times 10^{9} / \mathrm{l}\right)$ & $238.3 \pm 66.8$ & $235.8 \pm 69.9$ & 0.77 \\
\hline MPV (fL) & $8.58 \pm 0.92$ & $8.68 \pm 1.10$ & 0.45 \\
\hline MCV $\left(\mu^{3}\right)$ & $88.1 \pm 8.3$ & $89.06 \pm 6.1$ & 0.29 \\
\hline RDW $(\%)$ & $14.11 \pm 1.2$ & $14.46 \pm 1.3$ & 0.026 \\
\hline
\end{tabular}

Table 3. Correlations of CCV presence with clinical and laboratory variables

\begin{tabular}{lll}
\hline Variable & $\mathbf{r}$ & $\mathbf{p}$ \\
\hline Age & 0.083 & 0.18 \\
\hline Troponin & 0.146 & 0.02 \\
\hline Total diseased coronary & 0.229 & 0.001 \\
\hline Neutrophil & 0.218 & 0.001 \\
\hline Lymphocyte & -0.295 & 0.001 \\
\hline NLR & 0.391 & 0.001 \\
\hline Monocyte & 0.187 & 0.003 \\
\hline Coronary thrombus & 0.253 & 0.001 \\
\hline
\end{tabular}

a higher total number of diseased coronaries $(2.20 \pm 0.82$ vs. $1.82 \pm 0.76 ; p<0.001)$, total leukocyte count $(10.24$ \pm 2.68 vs. $9.31 \pm 2.62 ; p=0.006)$, red cell distribution width (RDW) $(14.46 \pm 1.32$ vs. $14.11 \pm 1.19 ; p=0.026)$, neutrophil count $(7.54 \pm 2.87$ vs. $5.74 \pm 2.12 ; p=0.002)$ neutrophil-lymphocyte ratio ( $4.68 \pm 2.13$ vs. $3.18 \pm 1.25$; $p=0.001)$, monocyte count $(0.78 \pm 0.32$ vs. $0.66 \pm 0.21$; $p=0.005)$ than the patients without collaterals. Lymphocyte count was lower in patients with collaterals when compared with the patients without collaterals (1.81 \pm 0.85 vs. $2.61 \pm 1.02$ respectively; $p=0.08$ ).

In the correlation analysis, while the presence of CCVs was significantly positively correlated with the total number of diseased vessels, the presence of coronary thrombus, to- 
Table 4. Clinical characteristics of patients with poor and good collaterals

\begin{tabular}{lccc}
\hline \multicolumn{1}{c}{ Variable } & $\begin{array}{c}\text { Poor } \\
\text { collateral } \\
\text { (Rentrop 1) }\end{array}$ & $\begin{array}{c}\text { Good } \\
\text { collateral } \\
\text { (Rentrop } \\
\mathbf{2 , 3})\end{array}$ & $\boldsymbol{p}$ \\
\hline Gender (M/F), $n$ & $45 / 15$ & $38 / 7$ & 0.24 \\
\hline Age (years) & $64.6 \pm 12.6$ & $59.7 \pm 11.8$ & 0.042 \\
\hline HT $(n, \%)$ & $32(53 \%)$ & $17(38 \%)$ & 0.11 \\
\hline Diabetes mellitus (\%) & $23(38 \%)$ & $10(22 \%)$ & 0.07 \\
\hline Total cholesterol (mg/dl) & $194 \pm 57$ & $197 \pm 46$ & 0.75 \\
\hline LDL cholesterol (mg/dl) & $122 \pm 44$ & $127 \pm 39$ & 0.52 \\
\hline Smoking $(n, \%)$ & $22(36 \%)$ & $25(55 \%)$ & 0.054 \\
\hline Previous PCI, $n(\%)$ & $8(13 \%)$ & $7(15 \%)$ & 0.74 \\
\hline Previous CABG, $n(\%)$ & $1(1.6 \%)$ & $0(0 \%)$ & 0.38 \\
\hline $\begin{array}{l}\text { Total diseased coronary } \\
\text { arteries }(n)\end{array}$ & $2.04 \pm 0.82$ & $2.3 \pm 0.81$ & 0.094 \\
\hline Coronary thrombus $(\%)$ & $68 \%$ & $74 \%$ & 0.026 \\
\hline $\begin{array}{l}\text { Presence of ischaemic } \\
\text { ECG changes (\%) }\end{array}$ & $75 \%$ & $71 \%$ & 0.84 \\
\hline Troponin (ng/ml) & $8.7 \pm 3.2$ & $11.8 \pm 5.5$ & 0.068 \\
\hline & & & \\
\hline
\end{tabular}

Table 5. Blood parameters of patients with poor and good collaterals

\begin{tabular}{lccc}
\hline \multicolumn{1}{c}{ Variable } & $\begin{array}{c}\text { Poor } \\
\text { collateral } \\
\text { (Rentrop 1) }\end{array}$ & $\begin{array}{c}\text { Good } \\
\text { collateral } \\
\text { (Rentrop } \\
\mathbf{2 , 3})\end{array}$ & $\boldsymbol{p}$ \\
\hline Hemoglobin $(\mathrm{g} / \mathrm{dl})$ & $12.99 \pm 1.86$ & $12.96 \pm 1.89$ & 0.92 \\
\hline $\begin{array}{l}\text { White blood cell count } \\
\left(10^{3} / \mu \mathrm{l}\right)\end{array}$ & $9.85 \pm 2.66$ & $10.01 \pm 2.51$ & 0.51 \\
\hline Neutrophil count $\left(10^{3} / \mu \mathrm{l}\right)$ & $6.72 \pm 2.17$ & $7.1 \pm 1.56$ & 0.048 \\
\hline Lymphocytes count $\left(10^{3} / \mu \mathrm{l}\right)$ & $2.08 \pm 0.63$ & $1.68 \pm 0.67$ & 0.042 \\
\hline Monocyte count $\left(10^{3} / \mu \mathrm{l}\right)$ & $0.66 \pm 0.21$ & $0.78 \pm 0.32$ & 0.047 \\
\hline Neutrophil/lymphocyte ratio & $3.18 \pm 1.25$ & $4.68 \pm 2.13$ & 0.003 \\
\hline Platelet count $\left(\times 10^{9} / 1\right)$ & $229.1 \pm 65.2$ & $244.9 \pm 75.7$ & 0.26 \\
\hline MPV $(\mathrm{fL})$ & $8.71 \pm 1.12$ & $8.63 \pm 1.07$ & 0.71 \\
\hline MCV $\left(\mu^{3}\right)$ & $88.9 \pm 7.1$ & $89.3 \pm 4.7$ & 0.70 \\
\hline RDW $(\%)$ & $14.47 \pm 1.2$ & $14.46 \pm 1.3$ & 0.95 \\
\hline
\end{tabular}

tal leukocyte count, neutrophil count, monocyte count and neutrophil-lymphocyte ration, it was significantly negatively correlated with lymphocyte count (Table 3). The total number of diseased vessels was significantly positively correlat- ed with cardiac troponin I ( $r=0.146, p=0.025)$. Cardiac troponin I was also significantly correlated with total leukocyte count, neutrophil count, and NLR $(r=0.326, p<0.001$; $r=0.343, p<0.001 ; r=0.239, p<0.001$; respectively). The presence of coronary thrombus was significantly positively correlated with neutrophil count $(r=0.310, p<0.001)$, NLR $(r=0.252, p<0.001)$ and platelet count $(r=0.295$, $p<0.001)$.

In the subgroup analysis of the patients with CCVs, the patients with good CCVs (Rentrop grade 2 and 3) were younger than the patients with poor CCVs (Rentrop grade 1) $(p<0.05)$. The total number of diseased coronaries between the patients with good CCVs and poor CCVs was not statistically different $(p=0.094)$. While the monocyte count and the neutrophil count was significantly increased in the group with good CCVs, the lymphocyte count was significantly lower in the group with good CCVs. Neutrophil to lymphocyte ratio was significantly higher in the group with good CCVs as compared to the group with poor CCVs ( $4.68 \pm 2.13$ vs. $3.18 \pm 1.25$ respectively; $p=0.003$ ). Coronary thrombus was detected more frequently in the group with good CCVs when compared to the group with poor CCVs $(p=0.026)$ (Tables 4 and 5).

\section{Logistic regression analysis}

Age, total leukocyte count, cTnI, NLR, monocyte count, neutrophil count, lymphocyte count, red cell distribution width (RDW) and total number of diseased vessels were included in our univariate analysis. Neutrophil to lymphocyte ratio, monocyte count, neutrophil count, lymphocyte count and total number of diseased vessels were found significant in univariate analysis. In a multivariate logistic regression model with a forward stepwise method, neutrophil count (OR $=1.997,95 \% \mathrm{CI}$ : 0.001-0.171, $p=0.047$ ), lymphocyte count $(\mathrm{OR}=2.012,95 \% \mathrm{CI}: 0.006-0.583$, $p=0.045)$, NLR $(\mathrm{OR}=5.244,95 \% \mathrm{CI}: 0.207-0.457$, $p<0.0001)$, and monocyte count $(\mathrm{OR}=2.733,95 \% \mathrm{CI}$ : $0.128-0.790, p=0.007)$ remained associated with the development of CCV after adjustment for variables found to be statistically significant in univariate analysis (Table 6). In the multivariate regression analysis of the subgroups with good CCVs and poor CCVs; we found that only NLR significantly predicts good CCVs within the NST-ACS patients (Table 7).

\section{Discussion}

The principal finding of our study is that increased total number of diseased coronaries, neutrophil count, monocyte count and NLR are predictors of coronary collateral development in patients with NST-ACS. In subgroup analyses, the increased NLR predicted the patients with good coronary collaterals in patients with NST-ACS.

Leukocytes are rapidly released into the circulation during periods of acute stress, such as trauma or acute 
Table 6. Multivariate logistic regression analysis of collateral circulation (good collateral group as reference group)

\begin{tabular}{lcccc}
\hline & \multicolumn{1}{c}{ Univariate analysis } & Multivariate analysis (forward) \\
\cline { 2 - 5 } & OR $(\mathbf{9 5 \%} \mathbf{C I})$ & $\boldsymbol{p}$ value & OR (95\% CI) & $\boldsymbol{p}$ value \\
\hline Troponin & $1.058(0.004-0.012)$ & 0.291 & - & - \\
\hline $\begin{array}{l}\text { Total number of diseaesed } \\
\text { coronary arteries }\end{array}$ & $2.008(0.002-0.234)$ & 0.046 & - & - \\
\hline White blood cell count & $-1.539(0.078-0.010)$ & 0.125 & - & 0.013 \\
\hline Neutrophil count & $-1.997(0.001-0.171)$ & 0.047 & $-2.510(0.023-0.190)$ & 0.049 \\
\hline Lymphocyte count & $2.012(0.006-0.583)$ & 0.045 & $1.979(0.001-0.570)$ & 0.005 \\
\hline Monocyte count & $2.733(0.128-0.790)$ & 0.007 & $2.803(0.132-0.754)$ & $<0.0001$ \\
\hline Neutrophil/lymphocyte ratio & $5.244(0.207-0.457)$ & $<0.0001$ & $5.386(0.214-0.461)$ & - \\
\hline RDW & $1.778(0.007-0.144)$ & 0.077 & - & - \\
\hline
\end{tabular}

Table 7. Logistic regression analysis of good collateral circulation

\begin{tabular}{|c|c|c|c|c|c|c|c|}
\hline \multirow[t]{2}{*}{ Model } & \multicolumn{2}{|c|}{ Unstandardized coefficients } & \multirow{2}{*}{$\begin{array}{c}\begin{array}{c}\text { Standardized } \\
\text { coefficients }\end{array} \\
\beta\end{array}$} & \multirow[t]{2}{*}{$t$} & \multirow[t]{2}{*}{ sig. } & \multicolumn{2}{|c|}{$\begin{array}{c}95 \% \text { CI } \\
\text { interval for B }\end{array}$} \\
\hline & B & std. error & & & & lower bound & upper bound \\
\hline (Constant) & 1.101 & 0.546 & & 2.017 & 0.046 & 0.017 & 2.186 \\
\hline Age & -0.009 & 0.005 & -0.163 & -1.737 & 0.085 & -0.019 & 0.012 \\
\hline Troponin & 0.004 & 0.004 & 0.082 & 0.867 & 0.388 & -0.005 & -0.20 \\
\hline Neutrophil & -0.123 & 0.052 & -0.357 & -2.369 & 0.020 & -0.226 & -0.020 \\
\hline Lymphocyte & 0.374 & 0.196 & 0.379 & 1.909 & 0.059 & -0.015 & 0.764 \\
\hline NLR & 0.220 & 0.072 & 0.705 & 3.065 & 0.003 & 0.077 & 0.362 \\
\hline Monocyte & 0.304 & 0.185 & 0.151 & 1.645 & 0.103 & -0.063 & 0.670 \\
\hline $\begin{array}{l}\text { Total diseased } \\
\text { coronary }\end{array}$ & -0.060 & 0.075 & -0.074 & -0.790 & 0.432 & -0.209 & 0.090 \\
\hline
\end{tabular}

Dependent variable: good collateral

and other markers (e.g., CD11b/CD18) of polymorphonuclear and monocyte activation has been reported in patients with acute ischaemic heart diseases $[12,13]$. Coronary collateral vessels confine myocardial ischaemia and have an influence on the prevention of myocardial infarct extension, and preserve the myocardium in patients with ACS [14-17]. Despite the fact that the underlying mechanisms are not fully revealed, myocardial ischaemic episodes, growth factors [especially, granulocyte-colony stimulating factor (G-CSF), fibroblast growth factor (FGF) and vascular endothelial growth factor (VEGF)], various cell types such as endothelial, monocytes, smooth muscle, shear stress and cytokines are likely factors that are responsible for collateral development during myocardial hypoxia [1921]. Also, the duration of angina pectoris and the extent of CAD are evident determinants of CCVs. Previously, the researchers have found that in the group with adequate collateral development, the Gensini score and relatedly the atherosclerosis severity was significantly higher than the group with inadequate collateral development [22]. In our study, also, the total number of diseased coronaries was higher in patients with CCVs as compared to the patients without CCVs.

Various studies have been published about the role of monocytes in he development of collateral angiogenesis $[23,24]$. Previously, the increased neutrophil count and NLR was found to be associated with poor collateral development in the patients with stable CAD [25]. Paradoxically, the neutrophil count and NLR was significantly increased in patients with CCVs in our study. We also found that increased NLR were significantly related with development of good coronary collaterals in patients with non ST-elevated acute coronary artery disease. Increased leukocytes and its subtypes have a major role in modulating the inflammatory response in the atherosclerotic acute ischaemic process [3]. During the ischaemic process, these inflammatory cells (neutrophils and monocytes) release metalloproteinases that dissolve the surrounding matrix 
and the basal membrane of the preformed vessel. Ischaemia sensitises the local vascular endothelial cells to the chemotactic and proliferative effects of various growth factors by upregulating their receptors. Granule proteins and cytokines from neutrophils induce monocyte recruitment. Endothelial cells migrate, proliferate and subsequently form a new vessel with a lumen [26]. Increased reactive oxygen species (ROS) production, MCP-1, VEGF and GCSF are at the corner stones of this angiogenic response. Granulocyte-colony stimulating factor promotes neovascularisation by releasing VEGF from neutrophils and bone marrow-derived cells of haematopoietic lineage $[27,28]$. The mechanisms that the neutrophil uses to kill microorganisms also has the potential to injure ischaemic tissue under special circumstances. Its paradoxical role in the pathophysiology of disease was particularly reported in some circumstances; diabetic retinopathy, sickle cell disease, renal microvasculopathy, stroke and acute coronary artery syndromes. In the study by Zhao et al., in the myocardium of post-MI patients, angiogenesis was mostly active in the infarcted myocardium in the first week coincident with increased neutrophilic activation and increased production of ROS, and antioxidant treatment significantly supressed this microvascular angiogenesis [29]. Leukocyte infiltration in the early phase of ischaemia is harmful, but this might also be an essential process for myocardial repair, in which angiogenesis, fibrosis and consequently tissue healing takes place [30]. Inflammation after tissue ischaemia, was associated with subsequent angiogenesis [31]. Thus, angiogenesis after myocardial ischaemia seems to be an substantial part of cardiac remodelling that responds to the injured tissue. In the study by Egami et al. [32] the researchers have observed that, in P-selectin knockout $\left(\mathrm{P}-\right.$ selectin $\left.^{--}\right)$mice, there was a decreased tissue inflammation and in response to this, decreased angiogenic cytokine release and consequently, ischaemia-induced angiogenesis was significantly impaired. That study demonstrated the importance of inflammation in angiogenesis. On the other hand, recently, there have been many published studies which report the role of neutrophils in the pathophysiology of angiogenesis [33, 34]. Neutrophils were reported to have the capability to polarise to different phenotypes during angiogenesis [35]. While different neutrophil phenotypes were suggested for tumoural angiogenesis, this also might be considered for post-ischaemia angiogenesis; this requires further molecular biological studies. Besides the change of the phenotype of the neutrophils, the apoptosis of the neutrophils is delayed by the cytokines that results in functional longevity and modulation of the neutrophils' functions [36]. In patients with acute coronary syndromes, the lifespan of the neutrophils was significantly lengthened as a result of the delay of polymorphonuclear neutrophil apoptosis as compared to the patients with stable angina or healthy controls. The cytokines interferon $\gamma$ (IFN- $\gamma$ ), GM-CSF and interleukin $1 \beta$
(IL-1 3 ) induced apoptosis delay in leukocytes [36]. This phenomenon might be responsible for the increase of neutrophil count and NLR in CCV development in patients with unstable coronary artery disease when compared to the patients with stable coronary artery disease. There might be a subclinical chronic inflammatory response in patients with unstable CADs; the leukocyte counts at admission may signify a 'subclinical chronic inflammatory response' rather than an acute inflammatory response to myocardial ischaemic attacks in patients with unstable coronary artery disease. Incidentally, compared to the blood neutrophils, those associated with coronary plaques, exhibited increased telomerase activity, which is also a significant marker reflecting prolonged neutrophil lifespan [37]. These data may provide an explanation for the response of such a chronic process (collateral development) to an 'acute' alteration in CBC (leukocyte increase). Apart from the cytokines mentioned above, some soluble mediators from activated platelets have an inhibitory impact on the apoptosis process, significantly prolonging leukocyte survival [36]. In relation to activated platelets, in our study, there was significant association between coronary thrombus formation and the neutrophil count, NLR and lymphocyte count.

Furthermore, there are published studies about neutrophil subpopulations [38, 39]. In the study by Christoffersson et al. [39], the researchers found evidence for multiple neutrophil subtypes and proposed a subset of neutrophils with angiogenic properties, releasing MMP-9 (matrix metalloproteinase 9). They proposed that the neutrophils may be plastic and could adopt to their environment by changing their phenotypes as mentioned above. Christoffersson et al. reported that neutrophil which releases MMP-9 aids in the development of new vasculature in transplanted pancreatic islets. Matrix metalloproteinase 9 is highly expressed in the vulnerable regions of the atherosclerotic plaque, and it has been suggested that it is causally involved in plaque rupture. These angiogenic neutrophils may play a role in CCV formation in the patients with acute coronary syndromes as well. During the atherosclerosis process, starting from the plaque activation, neutrophils may facilitate their phenotypes and may induce angiogenesis in severely diseased coronaries to relieve ischaemia in the related myocardial area. Our study is an observational study, and we hypothesise that during acute coronary syndromes, the leukocytes have a role not only in the vulnerability of the atherosclerotic plaques but also in the recruitment of the vessel formation.

There are some limitations to our study. Firstly, the number of patients is low, and an increased number of patients are needed. Secondly, we could not measure some inflammatory markers in our study, such as highly sensitive C-reactive protein (CRP), interleukins or chemokines (MCP-1) because of the technical insufficiency in our hospital. Thirdly, angiography may not detect most collaterals 
situated intramurally. Therefore, the collaterals visualised by angiography may not accurately quantify collateral circulation. But the effect of this problem on the collateral score would be the same in the two groups and thus should not change the interpretation of our results. Finally, the present study is a retrospective, observational one. However, the angiographic and clinical data belong to the same period and come from the same laboratory.

\section{Conclusions}

In patients with NST-ACS, the increased neutrophil count, monocyte count and NLR may guide clinicians in their opinion about the development of CCVs in severely diseased coronaries. High NLR may predict good collateral development in patients with NST-ACS.

\section{Authors declare no conflict of interest.}

\section{References}

1. Hoffman M, Blum A, Baruch R, et al. (2004): Leukocytes and coronary heart disease. Atherosclerosis 172: 1-6.

2. Yilmaz M, Tenekecioglu E, Arslan B, et al. (2013): White Blood Cell Subtypes and Neutrophil-Lymphocyte Ratio in Prediction of Coronary Thrombus Formation in Non-ST-Segment Elevated Acute Coronary Syndrome. Clin Appl Thromb Hemost Nov. 6 [Epub ahead of print].

3. Horne BD, Anderson JL, John JM, et al. (2005): Which white blood cell subtypes predict increased cardiovascular risk? J Am Coll Cardiol 45: 1638-1643.

4. Tayebjee MH, Lip GY, MacFadyen RJ (2004): Collateralization and the response to obstruction of epicardial coronary arteries. QJM 97: 259.

5. Meier P, Gloekler S, Zbinden R, et al. (2007): Beneficial effect of recruitable collaterals: a 10-year follow-up study in patients with stable coronary artery disease undergoing quantitative collateral measurements. Circulation 116: 975-983.

6. Regieli JJ, Jukema JW, Nathoe HM, et al. (2009): Coronary collaterals improve prognosis in patients with ischemic heart disease. Int J Cardiol 132: 257-262.

7. Koerselman J, van der Graaf Y, de Jaegere PP, et al. (2003): Coronary collaterals: an important and underexposed aspect of coronary artery disease. Circulation 107: 2507-2511.

8. Kocaman SA, Sahinarslan A, Akyel A, et al. (2010): The association of circulating monocyte count with coronary collateral growth in patients with diabetes mellitus. Acta Diabetol 47: 49-54.

9. Tamhane UU, Aneja S, Montgomery D, et al. (2008): Association between admission neutrophil to lymphocyte ratio and outcomes in patients with acute coronary syndrome. Am J Cardiol 102: 653-657.

10. Judkins MP (1967): Selective coronary arteriography: I. A percutaneous transfemoral technic. Radiology 89: 815.

11. Rentrop KP, Cohen M, Blanke H, et al. (1985): Changes in collateral channel filling immediately after controlled coronary artery occlusion by an angioplasty balloon in human subjects. J Am Coll Cardiol 5: 587-592.
12. Shah P, Galis Z (2001): Matrix metalloproteinase hypothesis of plaque rupture players keep piling up but questions remain. Circulation 104: 1878e1880.

13. Mazzone A, DeServi S, Ricevuti G, et al. (1993): Increased expression of neutrophil and monocyte adhesion molecules in unstable angina. Circulation 88: 358e363.

14. Cohen M, Rentrop KP (1986): Limitation of myocardial ischemia by collateral circulation during sudden controlled coronary artery occlusion in human subjects: a prospective study. Circulation 74: 469-476.

15. Fukai M, Ii M, Nakakoji T, et al. (2000): Angiographically demonstrated coronary collaterals predict residual viable myocardium in patients with chronic myocardial infarction: a regional metabolic study. J Cardiol 35: 103-111.

16. Sabia PJ, Powers ER, Ragosta M, et al. (1992): An association between collateral blood flow and myocardial viability in patients with recent myocardial infarction. N Engl J Med 327: 1825-1831.

17. Pretre R, Rickli H, Ye Q, et al. (2000): Frequency of collateral blood flow in the infarct-related coronary artery in rupture of the ventricular septum after acute myocardial infarction. Am J Cardiol 85: 497-499.

18. Arslan U, Kocaoğlu I, Balci M, et al. (2012): The association between impaired collateral circulation and non-alcoholic fatty liver in patients with severe coronary artery disease. J Cardiol 60: 210-214.

19. Van Royen N, Piek JJ, Schaper W, et al. (2001): Arteriogenesis: mechanisms and modulation of collateral artery development. J Nucl Cardiol 8: 687-693.

20. Matsunaga T, Warltier DC, Weihrauch DW, et al. (2000): Ischemia induced coronary collateral growth is dependent on vascular endothelial growth factor and nitric oxide. Circulation 102: 3098-3103.

21. Seiler C (2003): The human coronary collateral circulation. Heart 89: 1352-1357.

22. Zorkun C, Akkaya E, Zorlu A, et al. (2013): Determinants of coronary collateral circulation in patients with coronary artery disease. Anadolu Kardiyol Derg 13: 146-151.

23. Sherman JA, Hall A, Malenka DJ, et al. (2006): Humoral and cellular factors responsible for coronary collateral formation. Am J Cardiol 98: 1194-1197.

24. Chittenden TW, Sherman JA, Xiong F, et al. (2006): Transcriptional profiling in coronary artery disease: indications for novel markers of coronary collateralization. Circulation 114: 1811-1820.

25. Uysal OK, Turkoglu C, Sahin DY, et al. (2013): The relationship between neutrophil to lymphocyte ratio and coronary collateral circulation. Clin Appl Thromb Hemost [Epub ahead of print].

26. Arras M, Wulf DI, Scholz D, et al. (1998): Monocyte activation in angiogenesis and collateral growth in the rabbit hindlimb. J Clin Invest 101: 40-50.

27. Ohki YHB, Sato Y, Akiyama H, et al. (2005): Granulocyte colony-stimulating factor promotes neovascularization by releasing vascular endothelial growth factor from neutrophils. FASEB J 19: 2005-2007.

28. Powell TM, Paul JD, Hill JM, et al. (2005): Granulocyte colony-stimulating factor mobilizes functional endothelial progenitor cells in patients with coronary artery disease. Arterioscler Thromb Vasc Biol 25: 296-301.

29. Zhao W, Zhao T, Chen Y, et al. (2009): Reactive oxygen species promote angiogenesis in the infarcted rat heart. Int $\mathbf{J}$ Exp Pathol 90: 621-629. 
30. Carmeliet P (2003): Angiogenesis in health and disease. Nat Med 9: 653-660.

31. Sasaki K, Murohara T, Ikeda H, et al. (2002): Evidence for the importance of angiotensin II type 1 receptor in ischemia-induced angiogenesis. J Clin Invest 109: 603-611.

32. Egami K, Murohara T, Aoki M, et al. (2006): Ischemia-induced angiogenesis: role of inflammatory response mediated by P-selectin. J Leukoc Biol 79: 971-976.

33. Tazzyman S, Niaz H, Murdoch C (2013): Neutrophil-mediated tumour angiogenesis: subversion of immune responses to promote tumour growth. Semin Cancer Biol 23: 149-158.

34. Bekes EM, Schweighofer B, Kupriyanova TA, et al. (2011): Tumor-recruited neutrophils and neutrophil TIMP-free MMP-9 regulate coordinately the levels of tumor angiogenesis and efficiency of malignant cell intravasation. Am J Pathol 179: 1455-1470.

35. Fridlender ZG, Sun J, Kim S, et al. (2009): Polarization of tumor-associated neutrophil phenotype by TGF-beta: "N1" versus "N2" TAN. Cancer Cell 16: 183-194.

36. Garlichs CD, Eskafi S, Cicha I, et al. (2004): Delay of neutrophil apoptosis in acute coronary syndromes. J Leukoc Biol 75: 828-835.

37. Narducci ML, Grasselli A, Biasucci LM, et al. (2007): High telomerase activity in neutrophils from unstable coronary plaques. J Am Coll Cardiol 50: 2369-2374.

38. Kolaczkowska E, Kubes P (2012): Angiogenic neutrophils: a novel subpopulation paradigm. Blood 120: 4455-4457.

39. Christoffersson G, Vagesjo E, Vandooren J, et al. (2012): VEGF-A recruits a proangiogenic MMP-9-delivering neutrophil subset that induces angiogenesis in transplanted hypoxic tissue. Blood 120: 4653-4662. 